\section{ENSINO EM SAÚDE SOBRE OS CUIDADOS COM O NEONATO: ESTRATÉGIA DE PROMOÇÃO DA SAÚDE COM GESTANTES}

\author{
Health education on neonate care: strategy to promote health \\ with pregnan
}

\section{RESUMO}

Objetivo: Avaliar o conhecimento prévio de gestantes acerca dos cuidados com o neonato. Métodos: Optou-se por um método de caráter exploratório, com abordagem qualitativa, desenvolvido com 10 gestantes, em uma Organização não governamental, em Fortaleza, Ceará, Brasil. A coleta de dados foi realizada mediante entrevista semi-estruturada com questões sobre os cuidados primários aos neonatos. Resultados: $\mathrm{Na}$ análise das falas emergiram os assuntos mais geradores de dúvidas a respeito dos cuidados primários ao neonato, sendo realizado atividades de ensino em saúde esclarecendo tais práticas. Conclusão: Pode-se observar que o conhecimento prévio das mulheres grávidas acerca dos cuidados com o neonato eram empíricos e apresentavam limitações. Assim, as atividades de ensino em saúde propiciaram um momento de discussão e de esclarecimento de dúvidas.

Descritores: Educação em Saúde; Promoção da Saúde; Gestantes; Recém-nascido; Enfermagem

\begin{abstract}
Objective: The study aimed to evaluate the prior knowledge of pregnant women about neonatal care. Methods: We chose an exploratory method with a qualitative approach, developed with 10 pregnant women, in a non-governmental organization in Fortaleza, Ceará, Brazil. Data collection was performed through a semi-structured interview with questions about primary care for newborns. Results: In the analysis of the speech emerged the most questionable issues regarding the primary care to the newborn, being carried out health education activities clarifying such practices. Conclusion: It may be noted that the prior knowledge of pregnant women about neonatal care was empirical and limited. Thus, health teaching activities provided a moment of discussion and clarification of doubts.
\end{abstract}

Descriptors: Health Education; Health Promotion; Pregnant Women; Newborn; Nursing.
Artigo Original

1) Universidade de Fortaleza - UNIFOR Fortaleza - (CE) - Brasil

2) 4 saberes Cursos de Especialização e qualificação - Fortaleza (CE) - Brasil

3) Escola Superior de Enfermagem do Porto - ESEP - Porto - Portugal

4) Instituto Centro de Ensino Tecnológico CENTEC - Fortaleza (CE) - Brasil

5) Art Médica Comércio e Representação de Produtos Hospitalares - Fortaleza (CE) - Brasil

Este artigo seguiu as normas e formatação estabelecidas pelo $5^{\circ} \mathrm{CIAIQ}$ - Congresso Ibero-Americano em Investigação Qualitativa. 


\section{INTRODUÇÃO}

A gestação é um período em que grandes expectativas são geradas, com misturas de sentimentos e frequentes dúvidas. Essas dúvidas são constantes e, muitas vezes, angustiantes, em especialmente quando se perpassa pela primeira gravidez. Nesta, a família, principalmente, a primípara sente dificuldade em como será a nova rotina da família, como ocorrerá o vínculo afetivo mãe/família e neonato, assim como, quais serão os cuidados primários que deve realizar com o seu tão esperado filho ${ }^{(1)}$.

Diante dessa frequente premissa surgiu o objeto de estudo da pesquisa, a qual remete-se a avaliação do conhecimento prévio de gestantes sobre os cuidados primários a serem realizados junto ao neonato. A justificativa e a relevância do estudo perpassam pela importância de conhecer tais necessidades maternas e os cuidados primários ao neonato que serão oferecidos por essas gestantes, de modo a favorecer as estratégias de intervenções de ensino na busca pela promoção da saúde do binômio mãe-filho e da família.

Além disso, corrobora-se com estudiosos ${ }^{(2)}$, os quais referem que no período da gravidez e no puerpério imediato, a mulher mostra-se receptiva às mudanças e ao processamento de informações que possam ser revertidas em benefício do neonato, apoiando-se em atitudes e em escolhas que propiciem o desenvolvimento e nascimento saudável.

Assim, a mulher torna-se fundamental nesse processo de ensino em saúde em relação à família, cuidando da saúde de seus entes, como multiplicadora de informações e de ações que possam levar ao bem-estar do núcleo familiar e, consequentemente, à melhora da qualidade de vida. Portanto, a aquisição de hábitos e escolhas saudáveis proporcionam a mudança de comportamento, promovendo à promoção e manutenção de saúde do indivíduo ${ }^{(2)}$.

Sabendo que o cuidado com o neonato continua sendo gerador de grandes dúvidas entre as mães, pois elas desenvolvem o cuidar como uma prática intrínseca, baseada no empirismo do ser humano, já que é ela quem gera e acompanha todas as fases dessa criança. Diante disso, o profissional de saúde, especialmente o enfermeiro, por ser considerado educador em saúde, torna-se fundamental para orientar e recomendar a estas mães às práticas de promoção da saúde e prevenção de agravos, perante os cuidados primários que elas realizarão com seus filhos em domicílio ${ }^{(3)}$.

O conceito de promoção da saúde é anterior à Conferência de Ottawa, como é o caso do Informe Lalonde, primeiro documento oficial que trouxe a ideia de Promoção da Saúde, na perspectiva de melhoria das condições de saúde, tornando-se uma discussão na agenda global ${ }^{(4)}$.
Assim, essa promoção envolve a capacidade do indivíduo e seu coletivo de lidar com os condicionantes da saúde, estimulando a habilidade de escolha para a melhoria da qualidade de vida, por meio de estratégias de orientação e educação em saúde ${ }^{(5)}$.

Para a gestante, a puérpera e/ou neonato, as estratégias de promoção da saúde abordadas nos serviços de saúde estão relacionadas quase que, de maneira exclusiva, à consulta médica individual. Essas ações de saúde, conduzidas por profissionais de saúde de um modo intervencionista não proporcionam um acolhimento às ansiedades, às queixas, às dúvidas rotineiras e aos temores associados culturalmente à gestação $^{(6)}$.

No que se referem aos enfermeiros, estas estratégias de promoção da saúde, muitas vezes, são inseridas durante as orientações no pré-natal ou na consulta de puericultura. Sendo, por vezes, esquecida durante o atendimento no setor hospitalar ou até mesmo em domicílio. Deste modo, tornase primordial o desenvolvimento de uma assistência e de atividades educativas de maneiras holística, envolvendo as condições sociais, ambientais e as relações familiares, de modo que a realidade da mulher gestante e/ou puérpera seja tratada na sua individualidade e na integralidade ${ }^{(7)}$.

Diante do exposto, objetivou-se avaliar o conhecimento prévio de gestantes acerca dos cuidados primários com o neonato.

\section{MÉTODOS}

Optou-se por um método de caráter exploratório, descritivo com abordagem qualitativa, que considera como sujeito da investigação, pessoas pertencentes a determinadas condições sociais, com suas atitudes, aspirações, crenças, significações e valores próprio( ${ }^{(8)}$.

O estudo foi realizado no espaço "Vida Feliz" do MISCOM-Movimento Integrado de Saúde Comunitária, uma Organização não governamental (ONG), na Cidade de Fortaleza, Ceará, Brasil. Com população adscrita, constituída por 495 famílias. Participaram da pesquisa dez gestantes, no último trimestre gestacional, obedecendo aos seguintes critérios de inclusão: estar integrada em um grupo familiar acompanhado pela ONG, sendo os de exclusão: o percentual de falta igual ou maior que $25 \%$ nas atividades de ensino em saúde e a não realização da visita domiciliar.

O estudo foi realizado em dois momentos: no primeiro, as gestantes foram contactadas por telefone e marcado um encontro para uma entrevista semiestruturada, a fim de avaliar o conhecimento prévio das gestantes que iriam participar do estudo sobre os cuidados com o RN, sendo composta por 13 perguntas norteadoras. 
A entrevista foi realizada pelas pesquisadoras com as gestantes e algumas variáveis de identificação foram consideradas, sendo elas: idade, escolaridade, estado civil, número de consultas de pré-natal, renda familiar, número de filhos, número de abortos. Foram realizadas perguntas como: quais os cuidados com o recém-nascido que mais the geram dúvidas? Quais assuntos você gostaria de assistir nas atividades dos nossos encontros sobre os cuidados com o seu bebê?

No segundo momento, realizaram-se as atividades de ensino em saúde em três dias consecutivos no salão localizado na própria ONG, o horário escolhido de acordo com disponibilidades das gestantes.

Foram organizados dois grupos, um pela manhã com seis gestantes e outro pela tarde com quatro gestantes. As atividades de ensino em saúde se iniciaram com um momento de apresentação das participantes e das pesquisadoras, aonde cada gestante era estimulada a falar um pouco de si, das suas ansiedades e expectativas e, por conseguinte as pesquisadoras também se apresentaram, seguindo para uma aula explicativa com o uso do álbum seriado, que contemplava as temáticas: o banho, a limpeza do coto umbilical, o que fazer diante das cólicas, limpeza e troca de fralda, aleitamento materno e Caderneta de Vacina do recém-nascido. E por fim as aulas práticas com o uso de recursos, tais como: boneco, banheira, materiais e produtos de higiene, Caderneta de Vacina fornecida pelo Ministério da Saúde ${ }^{(9)}$.

Para analisar os dados, foram utilizados: a transcrição das falas na íntegra, lidas e relidas exaustivamente, processamento, categorização, interpretação, e submetidas à análise de conteúdo ${ }^{(10)}$. Seguindo os passos nela previstos, evidenciando os significados emergentes no material, de acordo com os objetivos teóricos da pesquisa ${ }^{(8)}$.

Por se tratar de estudo que envolvem seres humanos, foram seguidos os princípios bioéticos previstos na Resolução 466/12 do Conselho Nacional de Saúde ${ }^{(11)}$, sendo aprovado pelo Comitê de Ética em Pesquisas da Universidade de Fortaleza - UNIFOR, pelo parecer $\mathrm{N}^{\circ}$ 270/20117. Os sujeitos que concordaram em participar da pesquisa estavam cientes dos objetivos da pesquisa, tiveram seu anonimato garantido, sendo identificados no texto com nomes fictícios com as denominações de gestantes (G1... G10).

\section{RESULTADOS E DISCUSSÃO}

Participaram do estudo dez gestantes, com faixa etária compreendida entre 16 e 36 anos. No que diz respeito ao prénatal, compareceram entre três a seis consultas. Destas, seis eram primíparas e quatro multíparas. E um dado relevante é que cinco delas não receberam nenhuma orientação sobre os cuidados primários com o neonato durante as consultas, sejam as realizadas pelo médico ou pelo enfermeiro.

O período pré-natal deve ser compreendido como o momento de preparação física e psicológica para o parto e principalmente para a maternidade, sendo um momento capaz de propiciar diálogos e intenso aprendizado e uma oportunidade de desenvolverem a educação em saúde como dimensão do processo de cuidar do binômio maternoinfantil ${ }^{(12)}$.

Quanto à escolaridade seis tinham ensino médio completo, três delas incompleto e uma tinha o ensino fundamental concluído. Quanto ao estado civil, cinco relataram ser casadas ou conviver em união estável e cinco solteiras. Destaca-se a prevalência da baixa renda e a necessidade de interromper os estudos ou atividade laboral em função dos cuidados com a gestação, preparação para a chegada do filho, a família e o domicílio.

O conhecimento prévio das gestantes a respeito dos cuidados com o neonato, fez perceber a necessidade de informações relacionadas principalmente aqueles que ajudam no controle do processo saúde-doença, como se observa:

Eu acho que eu não vou saber cuidar não, vou ter medo até de pegar. Banho eu não vou dar, nem mexer naquele umbigo. Não sei o que usa para limpar o umbigo não, não sei direito. (G2)

Na hora do banho usa um antisséptico líquido mesmo, né?! Mas sei que água tem que ser morna. (G1)

Acho que sei cuidar, só não sei se é da maneira certa. O meu maior medo são as cólicas, porque meu sobrinho tem muito e eu não sei o que vou fazer. Vou ficar doidinha! (G10)

As gestantes referiram o momento do primeiro banho como um período de grande ansiedade e medo, por esse ser uma das primeiras formas de comunicação que a mulher tem com filho. A fragilidade do corpo do RN associada principalmente a presença do coto umbilical e a dificuldade de sustentação do corpo, que causa insegurança e dificuldade na hora de realizar cuidados de higiene e pegar no colo $^{(13)}$.

O momento do banho do RN gera dúvidas desde o tipo de produto utilizado no corpo e cabelo, temperatura da água e sua frequência. Como a barreira epidérmica é imatura nos neonatos, a permeabilidade cutânea é muito elevada, alguns produtos podem promover mudanças nessa pele, pois muitos são direcionados ao uso infantil mas têm substâncias potencialmente tóxicas e prejudiciais à pele ${ }^{(14)}$.

Assim, o produto de limpeza ideal deve ser líquido, suave, sem fragrância, com pH neutro ou ligeiramente ácido, que não irrite a pele nem os olhos do neonato, nem altere o manto ácido protetor da superfície cutânea. A temperatura 
da água deve estar próxima à temperatura corporal, de $37^{\circ} \mathrm{C}-37,5^{\circ} \mathrm{C}$. Entretanto, alguns autores recomendam temperaturas ligeiramente mais baixas, correspondendo à temperatura da pele, $34^{\circ} \mathrm{C}-36^{\circ} \mathrm{C}^{(14)}$.

No que se refere à limpeza do coto umbilical, observouse um misto de insegurança e falta de conhecimento por parte das gestantes, associados, principalmente, a dúvida de que técnica e/ou produto utilizar para tratar o coto a fim de não infeccionar. Segundo estudiosos ${ }^{(15)}$, todos os anos ocorrem, em média, em todo o mundo, 4 milhões de mortes neonatais, das quais 99\% são sobretudo devido a infeções, estando as infeções do cordão umbilical entre as principais causas da mortalidade neonatal.

A maioria das gestantes trazia dúvidas quanto ao tipo de solução ou o não uso desta para o tratamento do coto. A limpeza do coto umbilical ainda é uma questão polêmica na literatura, pois produtos variados apresentam vantagens e desvantagens, sendo a técnica de manter o coto limpo e seco, realizada uma ou mais vezes ao dia, conforme necessidade, a mais aceita. A escolha do produto a ser utilizado, exceto em situações de surto infeccioso, não é uma prioridade. A clorexidina mostrou ser eficaz na redução da colonização e infecção do coto, porém retarda a mumificação, já o álcool a 70\% acelera este processo, mas não interfere na colonização ${ }^{(16)}$.

Conforme o Ministério da Saúde ${ }^{(16)}$ de todos os cuidados, o que tem se mostrado essencial para controle da infecção neonatal como um todo, é a lavagem das mãos com água e sabão e o uso de solução alcoólica antes do manuseio do neonato.

A cólica no neonato pode ser reconhecida pela mãe quando apresentar um choro súbito, forte, estridente, sem explicação e que nem as medidas de conforto realizadas habitualmente, conseguem aliviar. Esse choro pode durar horas e ser inconsolável, chegando a desajustar a relação mãe-neonato e em situações extremas gerar conflitos para o casal $^{(17)}$. Então, o como proceder diante da situação descrita anteriormente foi um dos assuntos mais comentados pelas gestantes durante a entrevista, causando-lhes ansiedade, pois além de afetar o neonato, também contribuía para que estas mães e os familiares envolvidos recorram a medidas não seguras.

Existem diversos métodos farmacológicos disponíveis para alívio de cólicas e gases em RN, inclusive são os mais indicados pelos profissionais de saúde, porém a massagem no abdômen, música, o movimentar das pernas do neonato simulando as pedaladas na bicicleta e a posição barriga com barriga também são alguns métodos eficazes de intervenção para controle das cólicas, visto que acalma o neonato pela proximidade com a mãe, traz segurança, além de promover o relaxamento que pode temporariamente diminuir o choro $\mathrm{e} o$ estresse relativo à dor ${ }^{(18)}$.
Outros assuntos que também foram abordados como: a limpeza e troca de fralda, o aleitamento materno e o uso da Caderneta de Vacina do neonato, conforme se pode perceber nestes relatos:

Quando ele fizer as necessidades dele, eu vou usar lenço umedecido, que é o melhor e trocar a fralda quando estiver cheia. Agora é bom ter cuidado para não ter assadura, tem que usar a pomada para não ter assadura. (G5)

Eu acho que é importante dar o peito, só não sei explicar o porquê, mas eu acho que ele sente sede né? Aí dar uma aguinha para lavar a boquinha e matar a sede. (G7)

Ah, o leite materno já é completo, a gente deve dar até seis meses, pode dar também até dois anos. Previne câncer de mama e evita até infecção (G9).

Eu sei que o bebê tem que tomar muitas vacinas, o filho da minha vizinha sofreu muito com essas vacinas. Será que é tão importante assim? Porque os bichinhos sofrem tanto. (G10)

A limpeza da pele associada à troca das fraldas gera muitas dúvidas, pois as gestantes não sabem qual o melhor produto e a técnica para a limpeza da pele, sendo esse um assunto de suma importância, pois a pele do neonato sofre um progressivo processo de adaptação ao ambiente extrauterino, o que exige cuidados especiais ${ }^{(14)}$. Dessa maneira, a recomendação é um conjunto de medidas que têm como objetivos principais manter essa área seca. $\mathrm{O}$ aparecimento de lesões na pele do neonato como as assaduras e dermatites são causadas, principalmente, pelo excesso de umidade, baixa frequência da troca e a pouca capacidade de absorção das fraldas, e uma vez que essa pele estiver macerada e em atrito com a fralda, pode ocasionar o aparecimento de lesões, além da colonização que pode ser facilitada $^{(19)}$.

Atualmente, existem várias opções a serem consideradas para a limpeza da pele do neonato, porém não se aconselha o uso de sabões e/ou sabonetes em contato direto com a pele, sendo a limpeza com água morna e algodão um dos métodos mais difundidos e aconselhados, principalmente nos neonatos do sexo feminino, devendo acontecer no sentido anteroposterior a fim de evitar contaminações ${ }^{(20)}$. Vale ressaltar que o uso de pós, principalmente, os talcos, é contraindicado em neonatos pelo risco de inalação acidental, que dentre outros problemas, pode causar pneumonite ou fibrose pulmonar ${ }^{(14)}$.

Dentre as gestantes participantes, emergiu uma temática bastante relevante a saúde materno-infantil que é o aleitamento materno, e pode-se perceber uma incerteza ou incompreensão quanto a prática da amamentação de maneira exclusiva, fato que gerou preocupação quanto ao sucesso desse processo. 
Observou-se que, muitas vezes, o aleitamento é descontinuado, ou deixa de ser exclusivo devido à insegurança da puérpera que se sente como a principal responsável em prover alimentação para o filho ${ }^{(21)}$. Vale ressaltar, que existem vários fatores contribuintes para o aumento do desmame precoce, que pode ser realizado por mães de qualquer idade, dentre eles: o desconhecimento da sua importância para a saúde do binômio mãe-filho, as práticas e crenças familiares e culturais, atividade laboral, nível de escolaridade materna, entre outros ${ }^{(22)}$.

Outro importante ponto de atenção foi a dificuldade que algumas gestantes apresentaram para compreender o significado de amamentação exclusiva. Três das dez participantes relataram que iriam fazer uso de água e chás durante o aleitamento, mesmo após as orientações; como justificativa, referiam as orientações das avós e/ou outros membros da família como fatores decisivos nas suas atitudes.

Diante o exposto, é válido salientar que os familiares exercem grande influência nos cuidados com esse RN e que o comportamento materno frente à amamentação é fortemente influenciado pela figura da avó, seja materna ou paterna, sendo considerada uma das figuras femininas mais importante na transmissão de informações e experiências sobre a lactação, podendo incentivar ou desestimular esta prática $^{(23)}$.

Destarte, mesmo sabendo que o incentivo ao aleitamento materno exclusivo até os seis meses de vida da criança, seja um processo educativo e permanente, deve-se ressaltar a importância do despertar da consciência crítica do indivíduo. Esta mudança só será percebida quando ele der marcas da transformação de seu saber, que não são imediatas $^{(7)}$.

No que se refere a vacinação dos neonatos, as gestantes revelaram-se bastante preocupadas com as possíveis reações adversas, chegando até a questionar a importância do cumprimento do calendário vacinal enquanto outras demostraram compromisso com o mesmo. O serviço de imunização é um recurso de prevenção de extrema importância, pois oferece proteção contra muitas doenças graves, de maneira individual e comunitária, reduzindo assim a circulação de agentes infecciosos ${ }^{(24)}$.

O profissional de enfermagem deve esclarecer a importância do acompanhamento do calendário vacinal através da Cardeneta de Saúde da Criança a fim de desmitificar alguns pré-conceitos trazidos pela gestantes, pois o processo de vacinação reflete naA redução da mortalidade infantil que é possibilitada por meio da implantação do Programa Nacional de Imunização (PNI) do Ministério da Saúde ${ }^{(24)}$. Ressaltando que o Brasil é um dos países que oferecem o maior número de imunobiológicos, de forma gratuita, aos grupos populacionais-alvo ${ }^{(25)}$.
A aproximação com as gestantes levou à compreensão de que a maternidade envolve uma série de dúvidas relacionadas aos cuidados primários ao $\mathrm{RN}$, aspectos subjetivos, culturais e familiares, podendo resultar em uma cadeia de conflitos emocionais, com repercussões no empoderamento materno. Conforme os relatos cheios de conhecimentos empíricos e insegurança, percebeu-se que o cuidado a essa clientela específica constitui um conjunto de ações biopsico-socioambiental que apontam o cuidado materno de qualidade como fundamental para o crescimento e desenvolvimento saudável e o bem-estar do neonato, refletindo na probabilidade de óbito nessa faixa etária ${ }^{(26)}$.

Com a análise das falas a seguir e das dúvidas trazidas pelas gestantes sobre as temáticas citadas percebe-se a necessidade de atividades educativas, como tecnologia baseada na educação e participação popular, oferecendo um espaço de diálogo, de escuta ativa, orientações e esclarecimentos de dúvidas e apoio psicológico a essas mães.

Eu amei, se pudesse faria de novo, não me arrependo (G5).

Eu percebi no curso que não era tão difícil assim, que eu podia cuidar da minha filha (G7).

Assim que ela nasceu, esqueci de tudo que aprendi, mas depois fui lembrando de tudo que as meninas tinham falado (G6).

A educação em saúde nasce da perspectiva da participação social, compreendendo que as verdadeiras práticas educativas somente têm lugar entre sujeitos sociais, devendo estar presente nos processos de educação permanente para a promoção da saúde ${ }^{(2)}$. Dessa maneira, ressalta-se o sucesso da educação em saúde que vai depender das atividades e de estratégias educativas desenvolvidas pelo profissional de saúde, tornando-se uma intervenção da ciência no cotidiano da população ${ }^{(27)}$. Sendo assim, o profissional deve estar atento para criar e recriar atividades que contenham métodos dinâmicos, criativos e reflexivos.

Diante disso e corroborando-se com a perspectiva do Paulo Freire, o cotidiano da prática educativa deve ser desenvolvido de modo participativo, em que o profissional de saúde ativamente transforme ou até mesmo reconstrua o saber considerando o contexto de vida dos usuários ${ }^{(7)}$. Assim, através do material didático-instrucional associado às orientações acredita-se na possibilidade de integrar a equipe de saúde, principalmente a enfermeira como educadora e as mães preparadas, dentro desse processo, para que dessa forma realmente possam intervir com segurança, atendendo as necessidades dos seus filhos ${ }^{(26)}$.

$\mathrm{O}$ recurso educacional pensado e utilizado nesse processo foi o álbum seriado, sendo este uma coleção de 
folhas organizadas por temas que podem conter desde textos a desenhos, dentre outras formatações explicativas. O álbum é bastante utilizado para a educação em saúde, tendo como vantagens: direcionar a sequência de exposição, possibilitar de forma imediata a retomada de qualquer folha/tema apresentado, simplificar as informações através de tópicos e utilizar figuras ilustrativas para facilitar a compreensão.

O recurso foi idealizado e desenvolvido pelas próprias pesquisadoras a fim de facilitar o entendimento das gestantes a respeitos de temas levantados por elas. Utilizouse o Microsoft Power Point 2010 para montar cada uma das fichas de orientações sobre os cuidados com o RN, a tecnologia foi impresso numa gráfica especializada, confeccionado em papel couchê, tamanho de folha A3, 420 x $297 \mathrm{~mm}$ em modo paisagem.

O álbum continha uma capa intitulada: Cuidando com carinho do seu filho - Um guia de orientação para mães, um sumário, um prefácio, aonde é ressaltada a importância do trabalho do profissional de saúde como educador e uma apresentação sucinta da tecnologia em saúde. As fichas de orientação foram divididas em sete temas, cada um dos temas ocupando de uma a sete páginas, com tópicos explicativos e ilustrações relacionadas ao assunto. Todas as informações estavam respaldadas por referências nacionais e internacionais.

O Álbum foi utilizado no segundo momento do estudo, aonde foram realizadas as atividades educativas. As falam emergiram após as apresentações com o recurso:

Os materiais que as meninas levaram eram muito bons, tinha até uma boneca! Eu achei legal demais, pois a gente via bem direitinho como era pra banhar. (G4)

Foi muito bom, porque elas levaram aquele livro com imagens e várias informações. Ajudou também porque a gente entendia tudo. (G10)

Dessa maneira é interessante ressaltar que o sucesso da educação em saúde vai depender das atividades e estratégias educativas desenvolvidas pelo profissional de saúde, tornando-se uma intervenção da ciência no cotidiano da população ${ }^{(27)}$. Sendo assim, o profissional deve estar atento para criar e recriar atividades que contenham métodos dinâmicos, criativos e reflexivos.

\section{CONSIDERAÇÕES FINAIS}

Por conseguinte, através da leitura dos depoimentos maternos, pode-se observar que o conhecimento prévio das mulheres grávidas acerca dos cuidados com o neonato eram empíricos e apresentavam limitações. E as atividades de ensino em saúde propiciaram um momento de discussão e de esclarecimento de dúvidas, podendo ser uma estratégia facilitadora no entendimento e prática acerca dos cuidados primários com o neonato. Assim, as gestantes mostram-se satisfeitas com os assuntos abordados e com as estratégias utilizadas, afirmando que estas facilitaram o entendimento.

A limitação desta pesquisa foi que durante o estudo foi percebido que a Unidade de Atenção Primária à Saúde da comunidade estavam desativadas devido à violência. Essa realidade justifica o baixo número de consultas de pré-natal e ajuda na desinformação da população estudada, principalmente no que se refere à saúde de sua criança, podendo ser esse um dos fatores que justifica o conhecimento superficial. O Álbum seriado, a primeiro momento, não foi validado, sendo essa uma atividade de suma importância que será realizada posteriormente.

Nesse cenário, salienta-se como estratégia de fortalecimento das práticas de cuidado com o neonato aprendidas nas atividades de ensino em saúde, a visita domiciliar. Tal estratégia pode propiciar um momento de avaliação e adaptação, por parte do profissional de saúde e principalmente o enfermeiro, a realidade ímpar encontrada de cada binômio mãe-filho.

\section{REFERÊNCIAS}

1. Corbellini VL, Santos BRL, Ojeda BS, Gerhart LM, Eidt OR, Stein SC, Mello DT. Nexos e desafios na formação profissional do enfermeiro. Rev Bras Enferm. 2010; 63(4):555-560.

2. Gomes LB, Merhy EE. Compreendendo a Educação Popular em Saúde: um estudo na literatura brasileira. Cad Saúde Pública. 2011;27(1):7-18.

3. Linhares EF, Silva LWS, Rodrigues VP, Araújo RT. Influência intergeracional no cuidado do coto umbilical do recém-nascido. Texto Contexto Enfermagem. 2012;21(4): 828-36.

4 .Lopes MSV, Saraiva KRO, Fernandes AFC, Ximenes LB. Análise do conceito de promoção da saúde. Texto Contexto Enferm. 2010;19(3):461-468.

5. Heidemann ITSB, Boehs AE, Fernandes GCM, Wosny AM, Marchi JG. Promoção da saúde e qualidade de vida: concepções da carta de ottawa em produção científica. Cienc Cuid Saude. 2012;11(3):613-619.

6. Souza VB, Roecker S, Marcon SS. Ações educativas durante a assistência pré-natal: percepção de gestantes atendidas na rede básica de Maringá-PR. Rev Eletr Enf [periódico na Internet]. 2011 [acesso em 2016 Nov 19]; 13(2):199-210. Disponível em: http://www.fen.ufg.br/ revista/v13/n2/v13n2a06.htm

7. Silva LD, Beck CLC, Dissen CM, Tavares JP, Budó MLD, Silva H S. (2012). O Enfermeiro e a Educação 
em Saúde: um estudo bibliográfico. Rev Enferm UFSM. 2012;2(2):412-419.

8. Minayo MSC, Deslandes SF, Gomes R. Pesquisa social: teoria, método e criatividade. $25^{\mathrm{a}}$ ed. Petrópolis: Vozes; 2010.

9. Ministério da Saúde (BR). Secretaria de de Atenção à saúde. Departamento de ações Programáticas Estratégicas, Área Técnica de Saúde da Criança e Aleitamento Materno. Caderneta de saúde da criança: Passaporte para a cidadania. Brasília; 2011.

10. Bardin L. Análise de conteúdo. São Paulo: Edições 70; 2015 .

11. Conselho Nacional de Saúde (BR), Comissão Nacional de Ética em Pesquisa. Resolução n 466 de 12 de dezembro de 2012. Diretrizes e normas reguladoras de pesquisa envolvendo seres humanos, Brasília: Ministério da Saúde; 2012.

12. Francisquini AR, Higarashi IH, Serafim D, Bercini LO. Orientações recebidas durante a gestação, parto e pósparto por um grupo de puérperas. Cienc Cuid Saude. 2011;9(4):743-751.

13. Leandro JS; Christoffel MM. Cuidado familial de recémnascidos no domicílio: um estudo de caso etnográfico. Texto Contexto Enferm. 2011;20(Esp):223-31.

14. Fernandes JD, Machado MCR, Oliveira ZNP. Prevenção e cuidados com a pele da criança e do recém-nascido. An Bras Dermatol [periódico na Internet]. 2011 [acesso em 2016 Nov 18];86(1):102-10. Disponível em: http:// www.scielo.br/pdf/abd/v86n1/v86n1a14.pdf

15. Luís S, Costa GA, Casteleiro C. Boas práticas nos puidados ao coto umbilical: um estudo de revisão. Millenium. 2014;47(jun/dez):33-46.

16. Ministério da Saúde (BR). Secretaria de Atenção à saúde. Departamento de ações programáticas e estratégicas. Atenção à saúde do recém-nascido: guia para os profissionais de saúde. Brasília; 2011.

17. Christoffel MM, Silva LR, Silva LR, Ferreira ACGV, Macedo EC. Cólica do lactente: um estudo descritivo das práticas de cuidados maternos para alivio da dor. Rev enferm UFPE [periódico na internet]. 2013 [acesso em 2016 Nov 18];7(10):5876-82. Disponível em: http:/www.revista.ufpe.br/revistaenfermagem/ index.php/revista/article/download/4788/7356.

18. Ramos EM, Silva LF, Cursino EG, Machado MED, Ferreira DSP. O uso da massagem para alívio de cólicas e gases em recém-nascidos. Rev enferm UERJ. 2014; 22(2):245-50.
19. Fluhr JW, Darlenski R, Taieb A, Hachem JP, Baudouin C, Msika P, Belilovsky C, Berardesca E. Functional skin adaptation in infancy - almost complete but not fully complete. Exp Dermatol. 2010;19(6):483-92.

20. Gomes ALM, Rocha CR, Henrique DM, Santos MA, Silva LR. Conhecimentos de familiares sobre os cuidados com recém-nascidos. Rev Rene. 2015;16(2):258-65.

21. Camarotti CM, Nakano AMS, Pereira CR, Medeiros CP, Monteiro JCS. Perfil da prática da amamentação em grupo de mães adolescentes. Acta Paul Enferm. 2011;24(1):55-60.

22. Gusmão AM, Béria JU, Gigante LP, Leal AF, Schermann LB. Prevalência de aleitamento materno exclusivo e fatores associados: estudo transversal com mães adolescentes de 14 a 16 anos em Porto Alegre, RS, Brasil. Ciênc saúde coletiva. 2013;18(11):33573368 .

23. Marques ES, Cotta RMM, Magalhães KA, Sant'Ana LFR, Gomes AP, Siqueira-Batista R. A influência da rede social da nutriz no aleitamento materno: o papel estratégico dos familiares e dos profissionais de saúde. Ciênc saúde coletiva. 2010;15(1):1391-1400.

24. Oliveira VG, Pedrosa KKA, Monteiro AI, Santos, ADB. Vacinação: o fazer da enfermagem e o saber das mães e/ou cuidadores. Rev. Rene [periódico na internet]. 2010 [acesso em 2016 Nov 18];11(esp):133141. Disponível em: http://www.revistarene.ufc.br/ edicaoespecial/a15v11esp_n4.pdf

25. Domingues CMAS, Teixeira AMS. Coberturas vacinais e doenças imunopreveníveis no Brasil no período 19822012: avanços e desafios do Programa Nacional de Imunizações. Epidemiol. Serv. Saúde. 2013;22(1):9-27.

26. Campos ACS, Gomes MNLG, Cunha ALAC, Cavalcante RC. Cartilha educativa: estratégia de cuidado domiciliar para a mãe do recém-nascido prematuro. Enferm Atual. 2011;11(62):28-31.

27. Alves GG, Aerts D. As práticas educativas em saúde e a Estratégia Saúde da Família. Ciênc saúde coletiva. 2011:16(1):319-325.

\section{Endereço para correspondência:}

Karla Maria Carneiro Rolim

Universidade de Fortaleza - UNIFOR

Mestrado Tecnologia e Inovação em Enfermagem MPTIE

Av. Washington Soares, 1321, Bloco M, Sala 07

Bairro: Edson Queiroz

CEP: 60811.905 - Fortaleza - CE - Brasil

E-mail: karlarolim@unifor.br 